\title{
Indicadores educacionais e a ideia da integração do ensino: o ensino médio na Amazônia sob análise
}

\section{Indicators educational and the idea of education integration: secondary education in the Amazon under review}

Ronaldo Marcos de Lima Aranjo - Doutor em Educação; professor da Faculdade de Educação da Universidade Federal do Pará, Belém-PA. E-mail: rlima@ufpa.br.

Doriedson do Socorro Rodrigues - Doutor em Educação; professor da Faculdade de Educação da Universidade Federal do Pará, Belém-PA. E-mail: doriedson@ufpa.br

João Paulo da Conceição Alves - Mestre em Desenvolvimento Regional; professor da Rede Estadual de Ensino do Amapá. Macapá-AP. E-mail: jpauloche@bol.com.br

\section{Resumo}

O trabalho analisa alguns indicadores educacionais do ensino médio em municípios da Amazônia brasileira, observando as variáveis reprovação, aprovação, abandono e distorção idade-série. A partir de dados do INEP, e sob abordagens quantitativa e qualitativa foram feitas análises referentes aos anos de 2002, 2007 e 2012, com destaque aos espaços rurais e urbanos. Os dados revelam a configuração atual de um ensino médio problemático nos centros urbanos, com a piora dos índices de fluxo na zona rural da Amazônia. O Pará e o Tocantins apresentam altos índices de reprovação em municípios longínquos dos centros urbanos e, portanto, distantes de um relativo desenvolvimento econômico. É imperiosa a necessidade de políticas públicas que permitam uma formação integrada em correlação às ações que impeçam a juventude em idade escolar entrar precocemente no trabalho, privando-a de uma formação totalizante e ampliada.

\section{Palavras-chave}

Amazônia. Educação. Ensino Médio. Ensino Médio Integrado.

\begin{abstract}
The paper analyzes some educational indicators of high school in municipalities of the Brazilian Amazon, noting the variables disapproval, approval, abandonment and age-grade. From INEP data, and under quantitative and qualitative approaches were made analysis for the years 2002, 2007 and 2012, with emphasis on rural and urban spaces. The data shows the realization of a troubled high school in urban centers, with the worsening of flow rates in rural Amazonia. Pará and Tocantins municipalities have high failure rates in remote municipalities of urban centers, and so distant a relative economic development. It is imperative the need for public policies that enable an integrated training in correlati on to actions that prevent the youth of school age go early at work, depriving it of a totalizing and expanded training for their lives.
\end{abstract}

\section{Keywords}

Amazon. Education. High school. Integrated high school. 


\section{INTRODUÇÃO}

Este trabalho apresenta um diagnóstico analítico sobre o Ensino Médio na Amazônia, apontando-se sugestões de ações e mudanças na sua organização nos municípios da Amazônia brasileira, de modo a contribuir para a melhoria da qualidade e da oferta desta etapa de ensino na região amazônica.

Introdutoriamente entende-se a região amazônica como um espaço marcado por uma rica diversidade natural e cultural, contudo, evidencia uma série de contrastes sociais. Ou seja, embora se revele uma região rica, onde algumas metrópoles e cidades apresentam índices de desenvolvimento industrial e econômico relevantes, ainda há, nesses mesmos aglomerados urbanos, baixos índices de desenvolvimento humano e/ou social.

Outrossim, em termos de trabalho, nessa região também observamse contrastes, haja vista a convivência desigual entre ilhas de modernidade tecnológica relacionadas à industrialização ao lado de formas de organização do trabalho muitas vezes consideradas primitivas. Ou seja, a tecnologia de ponta utilizada em empresas organizadas sob a égide do toyotismo convive, de forma conflituosa, com o extrativismo e com formas tradicionais de trabalho (ARAUJO; ALVES, 2013).

Neste contexto, orientados pelo desafio de formulação de estudos e ações de planejamento voltadas ao sistema de Ensino Médio da região, visamos aqui analisar alguns dados referentes aos fluxos desse nível de ensino, por município da Amazônia, considerando os índices de aprovação, reprovação, abandono e distorção idade-série.

Os dados foram obtidos do Instituto Nacional de Estudos e Pesquisas Educacionais Anísio Teixeira (INEP) referentes aos anos de 2002, 2007 e 2012, a partir dos quais foram estabelecidas e correlações entre as variáveis referentes aos fluxos do ensino médio, permitindo uma análise comparativa dessa etapa de ensino tanto na zona rural como urbana por municípios da Amazônia Legal. A opção pela abordagem desses fluxos baseou-se na hipótese de que estes expressam as suas particularidades e refletem a sua realidade enquanto unidade, como uma síntese desse processo.

Como critérios utilizados na filtragem e análise dos dados, foram selecionados somente os municípios com atendimento escolar do ensino médio com pelo menos 50 alunos, segundo o Censo Escolar do INEP ${ }^{1}$, delimitando o

\footnotetext{
Segundo o INEP, cerca de 98,43\% das escolas brasileiras participaram da coleta de dados para o Censo Educacional do ano de 2013. Os maiores estados da região amazônica, Pará e Amazonas, tiveram mais de 99\% de participação. Disponível em: < http://portal.inep.gov.br/ web/educacenso/mapa-das-escolas Z. Acesso em: 28 dez. 2013.
} 
universo às redes públicas de ensino, no âmbito estadual e federal, localizadas nas zonas urbana e rural dos municípios, que representam cerca de $90 \%$ do total de matrículas no Brasil e 93\% na Região Norte. De fato, devido à rede estadual abranger a maior parte das matrículas no ensino médio em todo o país, esta terá predominância na análise dos dados.

Contudo, nessas análises foram desconsiderados os dados de aprovação, reprovação ou abandono dos municípios que apresentaram percentuais equivalentes a $0 \%$ ou $100 \%$, pois, diante das contradições do sistema educacional brasileiro, os dados gerados com essa proporção podem revelar imprecisões ou descontextualizar a realidade das escolas, sugerindo-nos equívocos nos registros.

Em termos de objetivos, busca-se compreender como vêm sendo implementados o fluxos do ensino médio na região amazônica, observando os índices elencados, visando responder especificamente qual perspectiva de ensino médio interessa aos trabalhadores enquanto processo de formação integral, englobando aspectos culturais, econômicos, científicos, desportivos e de trabalho na sociedade brasileira e no mundo, a fim de subsidiar a indicação de estratégias para o fomento de um sistema de ensino médio que permita impulsionar o desenvolvimento da região amazônica numa vertente humanizadora. ${ }^{2}$

Neste sentido, o trabalho foi estruturado em duas seções. $\mathrm{Na}$ primeira, empreendeu-se uma análise da situação do ensino médio no Brasil, questionando o panorama atual, no sentido de romper com a dualidade que vem se consolidando no processo educativo destinado aos trabalhadores, advogando-se pela necessidade de implantar um ensino médio sob uma perspectiva integrada. $\mathrm{Na}$ segunda seção apresentamos os resultados da pesquisa referentes ao fluxo do ensino médio na Amazônia, a partir das categorias Aprovação/Reprovação, Abandono e Distorção Idade-Série.

\section{O ENSINO MÉDIO NO BRASIL}

Nesta seção apresentamos uma reflexão sobre o ensino médio no contexto brasileiro, observando a sua função social, a partir do contraste entre os interesses dos trabalhadores e os do capital, a fim de se apontar uma perspectiva educacional oposta à dualidade que se tem empreendido para os sujeitos que vivem do trabalho, defendendo a proposta de formação integral.

\footnotetext{
Utilizamos o conceito de humanização segundo a afirmação de Marx e Engels (1978), de que o homem se humaniza pelo trabalho, uma vez que é por seu intermédio que ocorre a produção dos meios capazes de satisfazer as suas necessidades humanas, ao mesmo tempo em que cria novas necessidades. É justamente desta maneira que o homem se caracteriza como pertencente ao gênero humano, tornando-se diferente dos animais.
} 


\subsection{CONTEXTO E FUNÇÃO SOCIAL DO ENSINO MÉDIO BRASILEIRO}

Como consagrado na Lei de Diretrizes e Bases da Educação Nacional (LDB), o ensino médio consiste na etapa de transição entre o ensino fundamental e a educação superior (BRASIL, 1996). Trata-se da última etapa da educação básica, tendo como funções, definidas no artigo 35 da referida Lei, a consolidação e o aprofundamento dos conhecimentos adquiridos no ensino fundamental, a formação básica para o trabalho, o aprimoramento da noção de cidadania do educando e a apreensão dos fundamentos científico-tecnológicos dos processos produtivos.

Mas o seu caráter de transição não significa que deva ser considerado uma etapa de ensino com características essencialmente intermediárias, desprovidas de funções pedagógicas, curriculares e formativas próprias (GOMES et al., 2011). Pelo contrário, deve ser compreendido no contexto das necessidades humanas essenciais e enquanto etapa da educação básica voltada a promover o desenvolvimento da autonomia intelectual e emocional dos sujeitos, como fator primordial para a vida em comunidade.

No entanto, por ser a etapa da educação básica à qual se atribui a responsabilidade da preparação para o mercado de trabalho, o ensino médio tornou-se alvo privilegiado de políticas que visam à "necessidade" de a escola readequar-se para atender aos novos requisitos do padrão de acumulação (OLIVEIRA, 2011), como observado a partir dos anos 1990, principalmente, quando predominou na sociedade brasileira o ideário de que seria necessário um ensino médio que preparasse para a vida, mas entendida como a inserção do educando ao mercado de trabalho, minimizando e aligeirando a formação dos trabalhadores. Ou seja, essa preparação para a vida significava instaurar uma formação profissionalizante baseada em competências genéricas e flexíveis, preparando os indivíduos para se adaptarem às demandas do mercado de trabalho, na perspectiva da empregabilidade (GARCIA, 2012), deturpando-se, assim, a compreensão da realidade ao se atribuir ao trabalhador a responsabilidade pela busca do emprego, desconsiderando que se vive uma crise estrutural do capitalismo, com um aumento do desemprego (FORRESTER, 1997).

E, nessa perspectiva de se promover uma educação direcionada para a empregabilidade, para o mercado, tem-se advogado uma formação pautada em competências. Todavia, há de se entender que o caminho formativo norteado por competências ${ }^{3}$ não corrobora a educação do indivíduo em seu sentido pleno, dominando uma gama de conhecimentos enquanto unidade teórico-prática que lhe permita o exercício da cidadania no mundo do trabalho, da cultura, da

\footnotetext{
Sobre a Pedagogia das Competências, ver Araújo (2001).
} 
ciência, do desporto e outros campos. Pelo contrário, inocenta-se a lógica do capital dos problemas sociais e das políticas que a sustentam, colocando nas mãos do trabalhador a culpabilidade pela sua não empregabilidade. Nas palavras de Sennett (1999) e de Frigotto (2004), entendemos que:

É nesse contexto que a pedagogia das competências e da empregabilidade expressa, no plano pedagógico e cultural, a ideologia do capitalismo flexível, nova forma de intensificar a exploração do trabalho e de "corrosão do caráter", num contexto cujo "lema é: Não há longo prazo" (SENNETT, 1999). Uma ideologia que aumenta sua eficácia na medida em que efetiva a interiorização ou subjetivação de que o problema depende de cada um, e não da estrutura social, das relações de poder. Trata-se de adquirir o "pacote" de competências que o mercado reconhece como adequadas ao "novo cidadão produtivo. Por isso o credo ideológico reitera que a "empregabilidade é como a segurança agora se chama (FRIGOTTO, 2004, p. 197).

Diferentedessa posição formativa pautada em competências, compreendemos que o desafio colocado para esta etapa de ensino é de organizá-la de modo suficiente, em quantidade e qualidade, para que todos tenham acesso e aproveitamento para desenvolver amplamente as suas capacidades e alcançar a autonomia.

\section{ENSINO MÉDIO NA AMAZÔNIA E ANÁLISES SOBRE ALGUNS INDICADORES: APROVAÇÃO, REPROVAÇÃO, ABANDONO E DISTORÇÃO IDADE-SÉRIE}

As análises sobre o fluxo do Ensino Médio no interior da Amazônia pressupõem a compreensão das categorias utilizadas para o tratamento dos dados, a saber: aprovação, reprovação, abandono e distorção idade-série.

Considera-se aprovação a submissão dos alunos a processos de ensino e aprendizagem em função da frequência à escola no decurso do ano letivo. Neste sentido, associa-se a um conjunto de disciplinas e conteúdos programáticos as atividades pedagógicas que são avaliadas na dinâmica da sala de aula, indicando, ao final do período letivo, o aproveitamento do educando e a sua condição de aprovado ou reprovado, de acordo com o os níveis de aprendizagem que podem ou não ter sido desenvolvidos (BRASIL, 2013).

Além destas duas situações, o aluno pode abandonar a escola por motivos diversos. Sleb (2013) considera que o conceito de abandono traz uma perspectiva diferente, que leva em consideração a condição que antecede ao abandono escolar, bem como a possibilidade de uma correlação entre os motivos que levam os jovens a buscar sua formação e depois abandonar a escola, podendo haver a influência de fatores externos e internos ao ambiente escolar. 
Neste estudo, a utilização de dados sobre a distorção idade-série é fundamental, e se justifica por ser um dos reflexos do fluxo escolar acidentado entre os alunos do ensino médio. A definição de distorção idade-série, portanto, parte da concepção de um sistema educacional seriado, considerando uma adequação entre a série e a idade do aluno. A partir das definições desses tipos de fluxos no sistema educativo brasileiro, nos propomos a analisar, neste trabalho, as taxas referentes ao fluxo escolar no ensino médio, com ênfase na região amazônica.

\subsection{O ACESSO AO ENSINO MÉDIO NO BRASIL}

O ensino médio tem se revelado como uma etapa da formação escolar em que se registram grandes problemas no sistema educacional quanto à atenção e ao atendimento da demanda deste segmento na rede pública de ensino. Nesse sentido, um dos principais problemas decorre da não garantia de sua universalização, pois há anos a oferta estagnou em torno de 80\%. Outro grave problema que aflige o ensino médio é a baixa qualidade, evidenciada em todos os levantamentos, oficiais ou não, relativos à avaliação da qualidade do ensino público brasileiro.

Se somarmos o número de jovens que não têm acesso ao ensino médio, com o número de jovens que abandonam e que são reprovados nesta etapa de ensino, observamos um resultado superior a dois milhões de jovens inseridos em um fluxo acidentado. Esta constatação nos leva a considerar o ensino médio um nível de ensino marcado por sérios problemas de fluxo e conclusão.

As matrículas de ensino médio no Brasil, na Região Amazônica, e em cada um dos estados desta região revelam esta fragilidade. Deve-se registrar que na região amazônica somente os estados do Pará e do Amazonas englobam $70 \%$ das matrículas no ensino médio, das quais 93\% são efetuadas nas escolas públicas, sendo $90 \%$ somente nas redes estaduais de ensino e $91 \%$ concentradas na zona urbana. Ou seja, há necessidade de um maior investimento de escolas para o ensino médio na zona rural, de modo que os estudantes possam ter uma formação integrada à sua realidade (INEP, 2011).

Depreendemos desses dados a necessidade de se ampliar a oferta de vagas pelo sistema público de ensino, primando-se por uma formação integrada que contemple as realidades urbanas e rurais, permitindo a manutenção do alunado no seu local de origem, integrado às suas características culturais.

Para a Amazônia, defendemos uma proposta de ensino médio pautada na integração, que pressupõe a construção de uma práxis revolucionária, para além de questões curriculares e reestruturação de programas e projetos de 
ensino, conforme Araújo \& Rodrigues (2010). Com base nesses autores, também compreendemos que a perspectiva integradora relaciona-se muito mais a uma questão política e filosófica, ou seja, depende "[...] muito mais do posicionamento que a instituição e o profissional da educação assumem frente à realidade do que aos procedimentos didáticos que são pautados pela organização do curso e que serão utilizados pelos docentes" (ARAUJO; RODRIGUES, 2010, p. 18).

A perspectiva de ensino médio integrado também pressupõe uma postura pedagógica de oposição às noções de capital humano, sociedade de conhecimento e pedagogias de competências, visto que obscurecem os conflitos de classe, transferindo para a classe trabalhadora os problemas na formação.

$\mathrm{Na}$ prática docente, o Ensino Médio Integrado pressupõe que o educador proporcione ao educando a apreensão dos fundamentos de campos científicos cujos estudos enfatizam a relação do homem com a natureza, facultando-lhes a capacidade de analisar tanto os "[...] processos técnicos que engendram o sistema produtivo [...]" quanto "[...] relações sociais que regulam a quem se destina a riqueza produzida [...]” (FRIGOTTO, 2005, p. 74). A análise dos dados sobre o rendimento escolar no ensino médio visa demonstrar a necessidade da integração do conhecimento para a efetivação do ensino e para uma formação escolar de qualidade.

\subsection{APROVAÇÃO NO ENSINO MÉDIO}

No ano de 2002, os maiores índices de aprovação no ensino médio estão localizados nos municípios de Rio Branco (AC), na rede federal, e Brejo Branco do Araguaia (PA), na zona rural paraense.

Também nos chama a atenção o fato de que dentre os dez municípios com maiores índices de aprovação no ano de 2002, oito estão localizados na zona urbana, sendo que apenas dois municípios estão localizados na zona rural da região amazônica, que também têm baixa cobertura. Por conseguinte, observamos que dos 30 municípios identificados, apenas seis estão localizados na zona rural - Brejo Grande do Araguaia (PA), Redenção (PA), Santarém (PA), Curionópolis (PA), Vale do Paraíso (RO) e Barra do Ouro (TO), conforme se constata nos dados da Tabela 1.

As escolas rurais, por apresentarem os piores índices de aprovação nos seus fluxos, devem ser entendidas como objetivo central para a busca de estratégias de aprimoramento, a partir de investimentos em infraestrutura, recursos didáticos e num amplo programa de formação e qualificação contínua de professores como suportes essenciais à sua qualificação. 
Tabela 1 - Maiores índices de aprovação no Ensino Médio no ano de 2002 por Municípios da Região Norte/Amazônica.

\begin{tabular}{c|c|c|l|c|c|c}
\hline Ano & Região & $\begin{array}{c}\text { Sigla } \\
\text { da } \\
\text { UF }\end{array}$ & Município & $\begin{array}{c}\text { Loca- } \\
\text { lização }\end{array}$ & Rede & $\begin{array}{c}\text { Taxa de } \\
\text { Aprovação - } \\
\text { Ensino Médio (\%) }\end{array}$ \\
\hline 2002 & Norte & AC & Rio branco & Urbana & Federal & 99,1 \\
\hline 2002 & Norte & PA & $\begin{array}{l}\text { Brejo Grande } \\
\text { do Araguaia }\end{array}$ & Rural & Estadual & 98,5 \\
\hline 2002 & Norte & AM & Anama & Urbana & Estadual & 98,0 \\
\hline 2002 & Norte & TO & Nazaré & Urbana & Estadual & 96,4 \\
\hline 2002 & Norte & TO & Conceição do & Urbana & Estadual & 96,2 \\
\hline 2002 & Norte & RR & Boa vista & Urbana & Federal & 95,6 \\
\hline 2002 & Norte & AM & Tapaua & Urbana & Estadual & 95,4 \\
\hline 2002 & Norte & AM & Ipixuna & Urbana & Estadual & 94,8 \\
\hline 2002 & Norte & TO & $\begin{array}{l}\text { São Valério da } \\
\text { Natividade }\end{array}$ & Urbana & Estadual & 94,2 \\
\hline 2002 & Norte & RO & Vale do Paraíso & Rural & Estadual & 93,7 \\
\hline 2002 & Norte & PA & Santarém & Rural & Estadual & 93,7 \\
\hline 2002 & Norte & PA & Curionópolis & Rural & Estadual & 93,6 \\
\hline 2002 & Norte & PA & Castanhal & Urbana & Federal & 92,8 \\
\hline
\end{tabular}

Fonte: Brasil/INEP (2002).

Esta mesma análise foi realizada com base nos dados de 2007 e verificouse um acréscimo do número de alunos da zona rural em relação a 2002. Nesse ano, dos dez municípios com os maiores índices de aprovação, cinco localizamse na zona rural. Seguindo esta constatação, dos 30 municípios identificados na região amazônica, 13 localizam-se na zona rural: Paraná (TO), Pedro Afonso (TO), Porto Nacional (TO), Carrasco Bonito (TO), Esperantina (TO), Careiro da Várzea (TO), Rio Sono (TO), Sandolândia (TO), Borba (AM), Manacapuru (AM), Acrelândia (AC), Porto Acre (AC) e Curionópolis (PA), conforme se observa nos dados da Tabela 2 . 
Tabela 2 - Maiores índices de aprovação no Ensino Médio em 2007 - municípios da região amazônica.

\begin{tabular}{l|l|c|l|c|c|c}
\hline Ano & Região & $\begin{array}{c}\text { Sigla } \\
\text { da UF }\end{array}$ & Município & $\begin{array}{c}\text { Locali- } \\
\text { zação }\end{array}$ & Rede & $\begin{array}{c}\text { Taxa de Aprovação } \\
- \text { Ensino Médio } \\
(\%)\end{array}$ \\
\hline 2007 & Norte & TO & Pau D'arco & Urbana & Estadual & 97,8 \\
\hline 2007 & Norte & RR & Boa Vista & Urbana & Federal & 97,0 \\
\hline 2007 & Norte & TO & Novo Alegre & Urbana & Estadual & 96,6 \\
\hline 2007 & Norte & TO & Carrasco Bonito & Urbana & Estadual & 95,8 \\
\hline 2007 & Norte & TO & Paraná & Rural & Estadual & 95,3 \\
\hline 2007 & Norte & TO & Pedro Afonso & Rural & Estadual & 95,3 \\
\hline 2007 & Norte & AC & Acrelândia & Rural & Estadual & 95,1 \\
\hline 2007 & Norte & TO & $\begin{array}{l}\text { São Felix do } \\
\text { Tocantins }\end{array}$ & Urbana & Estadual & 94,9 \\
\hline 2007 & Norte & AC & Porto Acre & Rural & Estadual & 94,7 \\
\hline 2007 & Norte & TO & $\begin{array}{l}\text { Careiro da } \\
\text { Crixás Do }\end{array}$ & Rural & Estadual & 94,4 \\
\hline 2007 & Norte & TO & Mateiros & Urbana & Estadual & 94,4 \\
\hline 2007 & Norte & TO & $\begin{array}{l}\text { Presidente } \\
\text { Kennedy }\end{array}$ & Urbana & Estadual & 94,4 \\
\hline 2007 & Norte & RR & Bonfim & Urbana & Estadual & 94,3 \\
\hline
\end{tabular}

Fonte: Brasil/INEP (2007).

Em 2012, Dos 30 municípios com os maiores índices de aprovação na região, os que obtiveram os menores índices localizam-se na zona rural, somando um total 13 (treze) municípios, destacando-se: Redenção (PA) e novamente os municípios de Borba (AM) e Barra do Ouro (TO). Entre os que alcançaram os índices mais altos na zona rural constam os municípios de Redenção (PA) e Bujari (AC). No entanto, reconhece-se que as escolas da zona urbana apresentaram os maiores índices de aprovação desta região. Nesta perspectiva, a rede estadual concentra os dois municípios com maiores índices de aprovação, conforme a Tabela 3 . 
Tabela 3 - Maiores índices de aprovação no Ensino Médio em 2012, por municípios da região amazônica.

\begin{tabular}{c|l|c|l|c|c|c}
\hline Ano & Região & $\begin{array}{c}\text { Sigla } \\
\text { da UF }\end{array}$ & \multicolumn{1}{|c|}{ Município } & $\begin{array}{c}\text { Locali- } \\
\text { zação }\end{array}$ & Rede & $\begin{array}{c}\text { Taxa de } \\
\text { Aprovação (\%) }\end{array}$ \\
\hline 2012 & Norte & PA & Redenção & Rural & Estadual & 98,8 \\
\hline 2012 & Norte & AC & Bujari & Rural & Estadual & 98 \\
\hline 2012 & Norte & TO & Mateiros & Urbana & Estadual & 97,1 \\
\hline 2012 & Norte & TO & Tupirama & Urbana & Estadual & 96,7 \\
\hline 2012 & Norte & AC & Porto Acre & Urbana & Estadual & 96,5 \\
\hline 2012 & Norte & TO & Taipas do Tocantins & Urbana & Estadual & 96,3 \\
\hline 2012 & Norte & AC & Jordao & Rural & Estadual & 96,2 \\
\hline 2012 & Norte & AM & Tapaua & Urbana & Estadual & 96,1 \\
\hline 2012 & Norte & RO & Primavera de Rondônia & Urbana & Estadual & 95,9 \\
\hline 2012 & Norte & AC & Envira & Urbana & Estadual & 95,7 \\
\hline 2012 & Norte & TO & $\begin{array}{l}\text { São Salvador do } \\
\text { Tocantins }\end{array}$ & Rural & Estadual & 95,4 \\
\hline 2012 & Norte & TO & Nazaré & Urbana & Estadual & 95,2 \\
\hline 2012 & Norte & AP & Oiapoque & Rural & Estadual & 95,1 \\
\hline 2012 & Norte & TO & Monte do Carmo & Rural & Estadual & 94,8 \\
\hline
\end{tabular}

Fonte: Brasil/INEP (2012).

No cômputo geral, partir dos anos de 2002, 2007 e 2012, os dados sobre aprovação a revelam que os municípios de Redenção (PA), Assis de Vasconcelos (AC) e Boa Vista (RR) mantiveram uma regularidade na obtenção os maiores índices de aprovação, sendo, em sua maioria, capitais e/ou centros urbanos dotados de maior infraestrutura e serviços. Por outro lado, os piores índices de aprovação concentram-se nos menores municípios da região, e na zona rural, o que pode ser um fato revelador da ausência de políticas públicas educacionais eficazes nesses municípios e, por conseguinte, para a zona rural da Amazônia Legal como um todo.

\subsection{REPROVAÇÃO NO ENSINO MÉDIO}

Destacamos que a reprovação no ensino médio constitui um problema geral da educação brasileira. No entanto, as dimensões não são homogêneas, configurando-se como problemas que se agravam nas regiões mais pobres do país. Os estados da região amazônica evidenciam esse processo educacional precário, com base nos índices que serão analisados a seguir. 
Neste sentido, as taxas de reprovação merecem destaque, pois apresentaram um progressivo aumento durante o período de 11 anos considerado neste estudo. Esta situação nos leva a inferir que o processo de reprovação no ensino médio brasileiro vem se intensificando consideravelmente.

Ao analisar a Tabela 4, desta vez fazendo o recorte da Região Norte, observa-se que a Amazônia Ocidental (representada pelos estados de Roraima, Amazonas e Rondônia) apresentou os maiores índices de reprovação no ano de 2002. Os estados de Roraima e Rondônia apresentaram os três maiores índices, sobretudo em dois municípios, distribuídos nas zonas urbana e rural. Com base nesses dados (Tabela 4), verificamos que entre os dez municípios com maiores índices de reprovação a parte da Amazônia Oriental continuou apresentando baixos índices nos mesmos estados antes referidos.

Outro dado que chama a atenção denota que dos 30 municípios com os maiores índices de reprovação no ano de 2002, onze localizam-se no estado do Pará, (Tucuruí, São João da Ponta, Belém, Paragominas, Palestina do Pará - nas zonas urbana e rural; Tomé-Açu, Novo Progresso, Itupiranga, Cametá e Faro). Novamente o estado do Pará concentra os piores índices de reprovação. A Tabela 4 revela os municípios da região que tiveram os maiores índices de reprovação no ano de 2002.

Tabela 4 - Maiores índices de reprovação no ensino médio em municípios da Região Norte em 2002.

\begin{tabular}{|c|c|c|c|c|c|c|}
\hline Ano & Região & $\begin{array}{l}\text { Sigla } \\
\text { da UF }\end{array}$ & Município & $\begin{array}{c}\text { Locali- } \\
\text { zação }\end{array}$ & Rede & $\begin{array}{c}\text { Taxa de } \\
\text { Reprovação (\%) }\end{array}$ \\
\hline 2002 & Norte & $\mathrm{RO}$ & Presidente Médici & Urbana & Estadual & 25,2 \\
\hline 2002 & Norte & $\mathrm{RO}$ & Presidente Médici & Rural & Estadual & 20,7 \\
\hline 2002 & Norte & $\mathrm{RO}$ & Candeias do Jamari & Urbana & Estadual & 20,6 \\
\hline 2002 & Norte & $\mathrm{AM}$ & Abel Figueiredo & Urbana & Estadual & 19,8 \\
\hline 2002 & Norte & $\mathrm{RO}$ & Porto Velho & Urbana & Estadual & 19,6 \\
\hline 2002 & Norte & $\mathrm{RR}$ & Normandia & Rural & Estadual & 19,2 \\
\hline 2002 & Norte & PA & Tucuruí & Urbana & Federal & 19,0 \\
\hline 2002 & Norte & $\mathrm{PA}$ & São João da Ponta & Urbana & Estadual & 18,4 \\
\hline 2002 & Norte & PA & Belém & Urbana & Federal & 18,2 \\
\hline 2002 & Norte & $\mathrm{RO}$ & Colorado do Oeste & Rural & Federal & 17,8 \\
\hline 2002 & Norte & $\mathrm{RO}$ & Buritis & Urbana & Estadual & 16,8 \\
\hline 2002 & Norte & TO & Araguatins & Rural & Federal & 16,3 \\
\hline 2002 & Norte & $\mathrm{AM}$ & Atalaia do Norte & Urbana & Estadual & 16,2 \\
\hline 2002 & Norte & $\mathrm{AM}$ & Tonantins & Urbana & Estadual & 16,2 \\
\hline 2002 & Norte & PA & Paragominas & Urbana & Estadual & 15,7 \\
\hline
\end{tabular}

Fonte: Brasil/INEP (2002). 
Nos chama a atenção também que a rede federal apresente três municípios entre os dez que mais reprovaram no ano de 2002, considerando que a rede federal tem apresentado os índices mais satisfatórios na educação básica na Região Norte, confirmados pelos dados do INEP (2002, 2007 e 2012).

Quando analisamos os índices de reprovação no ano de 2007, a situação se altera. A concentração desses índices apresenta novamente maior repercussão no estado do Pará, visto que entre os dez municípios com maiores índices de reprovação no ano de 2007, nove são paraenses, conforme a Tabela 5.

A problemática prossegue mesmo quando analisamos os 30 municípios identificados, 26 localizam-se no Pará, dentre os quais estão municípios do arquipélago de Marajó e da região metropolitana de Belém. Este mesmo estado obteve os seis piores índices de reprovação em 2007 (INEP, 2012). A partir da Tabela 5 podemos visualizar a problemática da reprovação no ano de 2007.

Tabela 5 - Maiores índices de reprovação no ensino médio em municípios da Região Norte em 2007.

\begin{tabular}{l|l|c|l|c|l|c}
\hline Ano & Região & $\begin{array}{c}\text { Sigla } \\
\text { da UF }\end{array}$ & \multicolumn{1}{|c|}{ Município } & $\begin{array}{c}\text { Locali- } \\
\text { zação }\end{array}$ & Rede & $\begin{array}{c}\text { Taxa de } \\
\text { Aprovação } \\
(\%)\end{array}$ \\
\hline 2007 & Norte & PA & Aurora do Pará & Urbana & Estadual & 95,8 \\
\hline 2007 & Norte & PA & Barcarena & Urbana & Estadual & 67,2 \\
\hline 2007 & Norte & PA & Aurora do Pará & Rural & Estadual & 61,4 \\
\hline 2007 & Norte & PA & Jacundá & Urbana & Estadual & 60,4 \\
\hline 2007 & Norte & PA & Santa Isabel Do Para & Rural & Estadual & 58,7 \\
\hline 2007 & Norte & PA & São João do Araguaia & Urbana & Estadual & 58,4 \\
\hline 2007 & Norte & AM & Coari & Urbana & Federal & 57,1 \\
\hline 2007 & Norte & PA & Santa Maria do Pará & Rural & Estadual & 57,1 \\
\hline 2007 & Norte & PA & Água Azul do Norte & Urbana & Estadual & 55,3 \\
\hline 2007 & Norte & PA & Belterra & Urbana & Estadual & 54,8 \\
\hline 2007 & Norte & PA & Limoeiro do Ajuru & Urbana & Estadual & 53,9 \\
\hline 2007 & Norte & PA & Ourilândia do Norte & Urbana & Estadual & 49,4 \\
\hline 2007 & Norte & PA & Tucumã & Urbana & Estadual & 47,9 \\
\hline 2007 & Norte & AP & Pracuúba & Urbana & Estadual & 47,4 \\
\hline
\end{tabular}

Fonte: Brasil/INEP (2007).

Quando analisamos esses mesmos índices no ano de 2012, percebemos que, em números absolutos, os estados do Pará e Tocantins apresentam os maiores índices 
de reprovação. Novamente o Pará assume a dianteira quando se trata dos piores índices de reprovação da Amazônia, seguido pelo Tocantins. Há predominância do ensino médio na zona urbana, centrado na rede estadual de ensino.

Neste caso, sugere-se que as escolas localizadas nas zonas rurais dos respectivos municípios ressentem-se de escolas com atendimento ao nível médio e, quando dispõem, estão entre as mais desqualificadas no que se refere aos índices de aprovação, reprovação e abandono. Os da Tabela 6 confirmam esta afirmação.

Tabela 6 - Maiores índices de reprovação no ensino médio em municípios da Região Norte em 2012.

\begin{tabular}{c|c|c|l|c|c|c}
\hline Ano & Região & $\begin{array}{c}\text { Sigla da } \\
\text { UF }\end{array}$ & Município & $\begin{array}{c}\text { Locali- } \\
\text { zação }\end{array}$ & Rede & $\begin{array}{c}\text { Taxa de Aprovação } \\
- \text { Ensino Médio } \\
(\%)\end{array}$ \\
\hline 2012 & Norte & PA & Gurupá & Urbana & Estadual & 44,7 \\
\hline 2012 & Norte & TO & $\begin{array}{l}\text { São Miguel do } \\
\text { Tocantins }\end{array}$ & Rural & Estadual & 36,2 \\
\hline 2012 & Norte & TO & Peixe & Urbana & Estadual & 34 \\
\hline 2012 & Norte & TO & Gurupi & Urbana & Federal & 33,3 \\
\hline 2012 & Norte & RO & $\begin{array}{l}\text { São Francisco do } \\
\text { Guaporé }\end{array}$ & Urbana & Estadual & 31 \\
\hline 2012 & Norte & PA & Oriximiná & Urbana & Estadual & 31 \\
\hline 2012 & Norte & RR & Caracaraí & Urbana & Estadual & 30,4 \\
\hline 2012 & Norte & AM & Alapuã do Oeste & Urbana & Estadual & 30,2 \\
\hline 2012 & Norte & PA & Uruará & Urbana & Estadual & 29,2 \\
\hline 2012 & Norte & PA & Faro & Urbana & Estadual & 29,1 \\
\hline 2012 & Norte & AM & Uarini & Urbana & Estadual & 29,1 \\
\hline 2012 & Norte & AP & Laranjal do Jari & Urbana & Federal & 28,8 \\
\hline 2012 & Norte & PA & Rurópolis & Urbana & Estadual & 28,6 \\
\hline 2012 & Norte & PA & Barcarena & Urbana & Estadual & 28 \\
\hline
\end{tabular}

Fonte: Brasil/INEP (2007).

Os dados referentes à reprovação nos anos de 2002, 2007 e 2012 apontam o Pará com o maior número de municípios com índices de reprovação. Outra constatação importante refere-se à localização desta problemática nas zonas rurais, em muitos casos, em municípios distantes dos principais centros urbanos dos estados identificados. Foram observados altos índices de reprovação nos municípios Faro (PA) e Pau d'Arco (TO) e, portanto, são exemplos da afirmação acima. 
Ainda sobre os dados de reprovação, referenda-se, por exemplo, a análise que se refere à concentração em municípios de economias frágeis. Estes índices mantiveram-se constantes nos anos de 2002, 2007 e 2012, a exemplo dos municípios Presidente Médici (PA), Candeias do Jamari (RO), Abel Figueiredo (PA) (em 2002); Santa Isabel do Pará (PA), São João do Araguaia (PA), Coari (AM) (em 2007), além de Gurupá (PA), São Francisco do Guaporé (AM) e Itapuã do Oeste (RO) (em 2012).

Os problemas no processo de aprovação/reprovação no ensino médio são determinados pelas condições históricas da educação brasileira e se aprofundam no contexto amazônico. Como problemas estruturais neste processo, podemos apontar a dualidade no ensino e a (des)qualificação dos professores como dois grandes desafios deste nível de ensino.

O primeiro deles refere-se à lógica de organização do ensino, e como se relaciona ao processo de divisão social do trabalho. Campelo (2009), ao analisar a dualidade no ensino e define-a como uma fragmentação da escola, a partir da qual se definem caminhos distintos segundo a classe social, repartindo os indivíduos em lados antagônicos na divisão do trabalho. O dualismo da escola no modo capitalista de produção se manifesta como resultado de mecanismos pedagógicos internos, de destinação de 'uns e não outros'. Nessa concepção, para apreender a dualidade estrutural característica da escola capitalista é necessário colocar-se do ponto de vista daqueles que são excluídos dela.

De fato, as formas de implantação do Ensino Médio em municípios da região amazônica precisam ser revistas, em favor de "uma nova postura pedagógica frente à realidade educacional" 4 , implicando o envolvimento docente nos debates sobre problemas sócio-político-econômicos que permeiam esta realidade, o que pressupõe o combate à visão dualista que coordenou os projetos educativos voltados para a classe trabalhadora e a implementação de novas formas de integração entre objetos de conhecimento, sujeitos aprendizes e os mediadores desse intercâmbio - os docentes. Os problemas gerados pela reprovação escolar podem ter como horizonte assumir uma atitude pedagógica integradora por parte dos docentes e da escola de modo geral (ARAUJO; RODRIGUES, 2010).

E essa atitude nos apresenta a análise sobre o segundo problema citado - daquilo que, segundo Araujo e Rodrigues (2010), reflete a ausência de uma política voltada para a "capacitação individual e coletiva, para uma leitura da

\footnotetext{
4 Neste texto, destacamos as condições pedagógicas para a construção do ensino integrado. Entretanto, Franco (2005) apresenta os sete pressupostos que devem orientar um ensino integrado: 1) um projeto de sociedade não dualista; 2) manter, na lei, a articulação entre o ensino médio de formação geral e a educação profissional; 3) a adesão dos gestores e professores responsáveis pela formação geral e específica; 4) articulação da instituição com os alunos e as famílias; 5) o exercício da democracia; 6) o resgate da escola como lugar de memória; e 7) a garantia de investimentos na educação.
} 
realidade que circunda a escola e a sociedade de um modo geral" (FRIGOTTO, 2008), permitindo ao educador a compreensão das razões políticas e filosóficas que motivam o combate ao dualismo imposto à educação brasileira e a busca pela união entre "[...] formação intelectual e produção material articulando teoria e prática no desenvolvimento dos fundamentos ou bases científicas que permitam entender o mundo das coisas e as relações sociais" (FRIGOTTO, 2008, p. 12-13).

Não menos importante, constata-se a necessidade de um envolvimento muito maior entre os sujeitos que se inserem no espaço escolar, incluindo a sua história de vida, suas origens de classe ou de fração de classe como ponto de partida para promover a integração entre conteúdos, métodos e formas, e suas experiências e vivências, seus conhecimentos (FRIGOTTO, 2008), compreendendo-se "[...] as crianças e jovens da escola básica como sujeitos de conhecimento, de saberes e produtores de sua vida material, cultural, simbólica e artística [...]" (Ibid., p. 13). Sem esse entendimento, o ensino integrado jamais se realiza, porque não se consegue estabelecer como princípio básico integrar dialeticamente os saberes produzidos pela classe trabalhadora na região amazônica e por aqueles que defendem o papel da escola como instituição de ensino.

\subsection{ABANDONO ESCOLAR NO ENSINO MÉDIO}

Quanto às análises sobre o abandono escolar no Ensino Médio, observamos que, em 2002, dos dez municípios com os maiores índices de abandono, predominantemente na rede estadual, o Pará foi o estado com maior número de municípios nesta situação. Também nos chama atenção o estado do Amapá, que de um total de 16 (dezesseis) municípios, três (cerca de 20\%) apresentam altos índices de abandono escolar, a exemplo da rede estadual rural do município de Laranjal do Jari. Esta afirmativa pode ser constatada nos dados da Tabela 7 .

Tabela 7 - Maiores índices de abandono no ensino médio em municípios da Região Norte em 2002.

\begin{tabular}{c|l|c|l|c|c|c}
\hline Ano & Região & $\begin{array}{c}\text { Sigla da } \\
\text { UF }\end{array}$ & \multicolumn{1}{|c|}{ Município } & $\begin{array}{c}\text { Locali- } \\
\text { zação }\end{array}$ & Rede & $\begin{array}{c}\text { Taxa de } \\
\text { Abandono (\%) }\end{array}$ \\
\hline 2002 & Norte & AP & Laranjal do Jari & Rural & Estadual & 88,1 \\
\hline 2002 & Norte & RR & Uiramutã & Urbana & Estadual & 54,3 \\
\hline 2002 & Norte & PA & Baião & Urbana & Estadual & 52,4 \\
\hline 2002 & Norte & AC & Assis Brasil & Urbana & Estadual & 49,1 \\
\hline 2002 & Norte & PA & Nova Ipixuna & Urbana & Estadual & 46,0 \\
\hline
\end{tabular}




\begin{tabular}{l|l|l|l|c|l|c}
\hline 2002 & Norte & PA & Palestina do Pará & Rural & Estadual & 44,1 \\
\hline 2002 & Norte & PA & Altamira & Rural & Estadual & 42,8 \\
\hline 2002 & Norte & PA & Novo Progresso & Rural & Estadual & 41,7 \\
\hline 2002 & Norte & AP & Tartarugalzinho & Rural & Estadual & 40,5 \\
\hline 2002 & Norte & PA & São Félix do Xingu & Urbana & Estadual & 39,6 \\
\hline 2002 & Norte & PA & Cachoeira Do Piriá & Urbana & Estadual & 36,9 \\
\hline 2002 & Norte & PA & Trairão & Urbana & Estadual & 36,2 \\
\hline 2002 & Norte & PA & São João de Pirabas & Urbana & Estadual & 36,0 \\
\hline 2002 & Norte & AP & Tartarugalzinho & Urbana & Estadual & 35,8 \\
\hline
\end{tabular}

Fonte: Brasil/INEP (2002).

Em 2002, o Pará concentrou os maiores índices de abandono, a despeito de ser um dos estados com maior número de municípios. Dos 10 municípios com maior índice de abandono, seis localizam-se neste estado e, desses, 50\% são na zona rural. Porém, esta constatação é comprometedora, visto que na zona rural o número de escolas/alunos é inferior, em comparação à zona urbana.

Em 2007, houve uma queda neste percentual, porém continuava preocupante, pois, entre os dez municípios com maiores índices de abandono, $40 \%$ situam-se na zona rural (Tabela 8). Esses números são bastante elevados, visto que, proporcionalmente, o número de escolas na zona rural é uma minoria em relação à zona urbana.

Tabela 8 - Maiores índices de abandono do ensino médio em municípios da Região Norte em 2007.

\begin{tabular}{c|c|c|l|c|c|c}
\hline Ano & Região & $\begin{array}{c}\text { Sigla } \\
\text { da UF }\end{array}$ & \multicolumn{1}{|c|}{ Município } & $\begin{array}{c}\text { Locali- } \\
\text { zação }\end{array}$ & Rede & $\begin{array}{c}\text { Taxa de Aprovação } \\
\text { Ensino Médio (\%) }\end{array}$ \\
\hline 2007 & Norte & AP & $\begin{array}{l}\text { Pedra Branca do } \\
\text { Amapari }\end{array}$ & Urbana & Estadual & 53,9 \\
\hline 2007 & Norte & PA & Salvaterra & Urbana & Estadual & 51,8 \\
\hline 2007 & Norte & PA & Dom Eliseu & Urbana & Estadual & 47,1 \\
\hline 2007 & Norte & PA & Anapu & Urbana & Estadual & 42,9 \\
\hline 2007 & Norte & PA & $\begin{array}{l}\text { Nova Esperança } \\
\text { do Piriá }\end{array}$ & Urbana & Estadual & 41,9 \\
\hline 2007 & Norte & PA & Novo Progresso & Urbana & Estadual & 41,6 \\
\hline 2007 & Norte & RO & $\begin{array}{l}\text { Governador Jorge } \\
\text { Teixeira }\end{array}$ & Rural & Estadual & 40,2 \\
\hline 2007 & Norte & PA & Cachoeira do Piriá & Urbana & Estadual & 39,5 \\
\hline 2007 & Norte & AP & Calçoene & Rural & Estadual & 39,2 \\
\hline
\end{tabular}




\begin{tabular}{c|c|c|l|l|l|c}
\hline 2007 & Norte & PA & Trairão & Urbana & Estadual & 37,4 \\
\hline 2007 & Norte & PA & $\begin{array}{l}\text { São Sebastião da } \\
\text { Boa Vista }\end{array}$ & Urbana & Estadual & 37 \\
\hline 2007 & Norte & PA & Alenquer & Urbana & Estadual & 36,6 \\
\hline 2007 & Norte & PA & $\begin{array}{l}\text { São Domingos do } \\
\text { Capim }\end{array}$ & Urbana & Estadual & 35,3 \\
\hline 2007 & Norte & PA & Ulianópolis & Urbana & Estadual & 34,3 \\
\hline 2007 & Norte & PA & Santarém Novo & Urbana & Estadual & 33,9 \\
\hline
\end{tabular}

Fonte: Brasil/INEP (2007).

No ano de 2012, destacam-se os índices de abandono no Pará. A Tabela 9 revela que os índices de abandono são preponderantes na rede estadual e que o estado do Pará concentra 12 dos 15 maiores índices de abandono na região amazônica. Destaca-se, ainda, que a maioria destes municípios localizase nas regiões paraenses do Baixo Amazonas e Marajó, que também enfrentam problemas sociais decorrentes dos altos índices de pobreza e isolamento dos principais serviços públicos. As maiores taxas de abandono referem-se a cidades do interior da Amazônia, onde o alcance das políticas públicas é bastante limitado.

Neste caso, os maiores índices de abandono concentram-se nos estados da parte oriental da Amazônia, visto que a maior incidência de abandono/evasão concentra-se em municípios dos estados do Pará e Amapá. Pode-se afirmar, ainda, que no Amapá (AP) os índices de abandono foram elevados, pois, dos seus 16 municípios, cinco estão entre os 30 maiores índices de toda a Amazônia (INEP, 2010). No Pará, os índices de abandono referem-se, em sua totalidade, à rede estadual, reiterando a fragilidade desta rede de ensino e a necessidade de se avançar na qualidade do ensino médio, como princípio formativo no estado do Pará (Tabela 9).

Tabela 9 - Maiores índices de abandono no ensino médio em municípios da Região Norte em 2012.

\begin{tabular}{c|c|c|l|c|c|c}
\hline Ano & Região & $\begin{array}{c}\text { Sigla da } \\
\text { UF }\end{array}$ & Município & $\begin{array}{c}\text { Locali- } \\
\text { zação }\end{array}$ & Rede & $\begin{array}{c}\text { Taxa de Abandono } \\
\text { Ensino Médio (\%) }\end{array}$ \\
\hline 2012 & Norte & AM & Alvarães & Rural & Estadual & 52,9 \\
\hline 2012 & Norte & AM & Anori & Rural & Estadual & 41,4 \\
\hline 2012 & Norte & AP & $\begin{array}{l}\text { Pedra Branca do } \\
\text { Amapari }\end{array}$ & Rural & Estadual & 39 \\
\hline 2012 & Norte & AP & Pracuúba & Rural & Estadual & 37,5 \\
\hline 2012 & Norte & PA & Xinguara & Rural & Estadual & 37,2 \\
\hline 2012 & Norte & PA & Chaves & Urbana & Estadual & 36,1 \\
\hline
\end{tabular}




\begin{tabular}{c|c|c|l|c|c|c}
\hline 2012 & Norte & PA & Benevides & Rural & Estadual & 35,7 \\
\hline 2012 & Norte & AP & Calçoene & Rural & Estadual & 35,7 \\
\hline 2012 & Norte & PA & Dom Eliseu & Urbana & Estadual & 34,6 \\
\hline 2012 & Norte & PA & $\begin{array}{l}\text { São Felix do } \\
\text { Xingu }\end{array}$ & Urbana & Estadual & 34,5 \\
\hline 2012 & Norte & PA & Jacundá & Rural & Estadual & 34,1 \\
\hline 2012 & Norte & RO & $\begin{array}{l}\text { Nova } \\
\text { Brasilândia } \\
\text { D'oeste }\end{array}$ & Urbana & Estadual & 34 \\
\hline 2012 & Norte & AP & Tartarugalzinho & Rural & Estadual & 33,6 \\
\hline 2012 & Norte & PA & Tailândia & Rural & Estadual & 33,3 \\
\hline 2012 & Norte & PA & $\begin{array}{l}\text { Magalhaes } \\
\text { Barata }\end{array}$ & Urbana & Estadual & 33,2 \\
\hline
\end{tabular}

Fonte: Brasil/INEP (2012).

Mencionamos também os menores índices de abandono nos anos de 2002, 2007 e 2012. As duas metrópoles da Amazônia (Manaus na rede federal e Belém na rede estadual) figuram entre os trinta menores índices de abandono no ensino médio no ano de 2002. Registra-se também a presença de outros importantes municípios paraenses, como Redenção, Santarém e Castanhal; e de três municípios do arquipélago de Marajó (Muaná, Anajás e São Sebastião da Boa Vista), a despeito desta microrregião apresentar IDHs (Índices de Desenvolvimento Humano) bastante baixos (Tabela 10).

Tabela 10 - Menores índices de abandono no ensino médio em municípios da Região Norte em 2002.

\begin{tabular}{c|c|c|l|c|c|c}
\hline Ano & Região & $\begin{array}{c}\text { Sigla } \\
\text { da UF }\end{array}$ & Município & $\begin{array}{c}\text { Localiza- } \\
\text { ção }\end{array}$ & Rede & $\begin{array}{c}\text { Taxa de } \\
\text { Abandono no } \\
\text { Ensino Médio (\%) }\end{array}$ \\
\hline 2002 & Norte & AM & Anama & Urbana & Estadual & 0,5 \\
\hline 2002 & Norte & AM & Manaus & Urbana & Federal & 0,8 \\
\hline 2002 & Norte & TO & Lavandeira & Urbana & Estadual & 1,3 \\
\hline 2002 & Norte & PA & Redenção & Rural & Estadual & 1,3 \\
\hline 2002 & Norte & TO & $\begin{array}{l}\text { Conceição do } \\
\text { Tocantins }\end{array}$ & Urbana & Estadual & 3,0 \\
\hline 2002 & Norte & PA & Muaná & Urbana & Estadual & 3,0 \\
\hline 2002 & Norte & TO & Araguatins & Rural & Federal & 3,4 \\
\hline 2002 & Norte & AM & Tapaua & Urbana & Estadual & 3,6 \\
\hline 2002 & Norte & PA & Ipixuna & Urbana & Estadual & 4,2 \\
\hline
\end{tabular}




\begin{tabular}{c|c|c|c|c|c|c}
\hline 2002 & Norte & RO & Vale do Paraiso & Rural & Estadual & 4,2 \\
\hline 2002 & Norte & PA & Anajás & Urbana & Estadual & 4,5 \\
\hline 2002 & Norte & RO & $\begin{array}{c}\text { Colorado do } \\
\text { Oeste }\end{array}$ & Rural & Federal & 4,7 \\
\hline 2002 & Norte & PA & Castanhal & Urbana & Federal & 4,9 \\
\hline 2002 & Norte & PA & Marabá & Urbana & Estadual & 5,0 \\
\hline 2002 & Norte & PA & Belém & Urbana & Federal & 7,5 \\
\hline
\end{tabular}

Fonte: Brasil/INEP (2002).

Quanto aos menores índices de abandono, registrou-se maior incidência nas zonas urbanas, mas também a ocorrência em sete municípios da zona rural, concentrados na rede estadual, e somente em cinco municípios na rede federal de ensino, o que é um número expressivo proporcionalmente, pelo baixo número de matrículas na rede federal.

Observamos, em seguida, que os menores índices de abandono em 2007 concentraram-se na zona rural e na rede estadual de ensino, apesar do registro na rede federal em cinco municípios, e um deles apresentou o menor índice de abandono de toda região amazônica.

Cabe enfatizar que as capitais Manaus (AM), Boa Vista (RR) e Palmas (TO) apresentaram baixos índices de abandono em 2007. Os estados do Pará e Tocantins obtiveram as menores taxas, em seis e sete municípios, respectivamente. Destes, deve-se destacar o estado do Tocantins, onde há mais municípios com os menores índices, embora não seja o maior estado e nem apresentar taxas relevantes de desenvolvimento na região norte. A tabela 11 apresenta os menores índices de abandono no ano de 2007:

Tabela 11 - Menores índices de abandono no ensino médio em municípios da Região Norte em 2007.

\begin{tabular}{c|l|c|l|c|c|c}
\hline Ano & Região & $\begin{array}{c}\text { Sigla } \\
\text { da UF }\end{array}$ & \multicolumn{1}{|c|}{ Município } & $\begin{array}{c}\text { Locali- } \\
\text { zação }\end{array}$ & Rede & $\begin{array}{c}\text { Taxa de } \\
\text { Abandono no } \\
\text { Ensino Médio (\%) }\end{array}$ \\
\hline 2007 & Norte & TO & Palmas & Urbana & Federal & 0,2 \\
\hline 2007 & Norte & PA & Aurora do Pará & Urbana & Estadual & 0,3 \\
\hline 2007 & Norte & TO & Pau D'arco & Urbana & Estadual & 0,4 \\
\hline 2007 & Norte & PA & Curralinho & Urbana & Estadual & 0,4 \\
\hline 2007 & Norte & TO & Lagoa da Confusão & Urbana & Estadual & 0,5 \\
\hline 2007 & Norte & PA & Tucuruí & Urbana & Federal & 0,5 \\
\hline 2007 & Norte & PA & Santa Isabel do Pará & Rural & Estadual & 0,5 \\
\hline
\end{tabular}




\begin{tabular}{c|l|c|c|c|c|c}
\hline 2007 & Norte & TO & Miranorte & Urbana & Estadual & 0,8 \\
\hline 2007 & Norte & TO & Piraque & Urbana & Estadual & 0,8 \\
\hline 2007 & Norte & AM & Manaus & Urbana & Federal & 1 \\
\hline 2007 & Norte & TO & Esperantina & Rural & Estadual & 1,2 \\
\hline 2007 & Norte & PA & Afuá & Urbana & Estadual & 1,3 \\
\hline 2007 & Norte & RR & Boa Vista & Urbana & Federal & 1,4 \\
\hline 2007 & Norte & PA & Colares & Urbana & Estadual & 1,4 \\
\hline
\end{tabular}

Fonte: Brasil/INEP (2007).

A análise sobre o problema do abandono escolar no ensino médio pode ser mais abrangente, considerando-se o ano de 2012. Novamente a rede federal apresentou os menores índices de abandono da região amazônica, neste caso, na zona rural do município de Colorado do Oeste (RO). Ao lado de Boa Vista (RR), os municípios mais populosos da Amazônia, Belém (PA) e Manaus (AM), obtiveram os menores índices de abandono de toda a região, concentrados na rede federal de ensino. Dos 15 municípios, apenas dois localizam-se na zona rural, o que pode ser considerado como um dado positivo neste caso, devido às históricas condições desfavoráveis na zona rural (Tabela 12).

Tabela 12 - Menores índices de abandono no ensino médio em municípios da Região Norte em 2012.

\begin{tabular}{|c|c|c|c|c|c|c|}
\hline Ano & Região & $\begin{array}{l}\text { Sigla } \\
\text { da UF }\end{array}$ & Município & $\begin{array}{l}\text { Locali- } \\
\text { zação }\end{array}$ & Rede & \begin{tabular}{|c|} 
Taxa de Abandono \\
no Ensino Médio (\%)
\end{tabular} \\
\hline 2012 & Norte & $\mathrm{RO}$ & Colorado do Oeste & Rural & Federal & 0,2 \\
\hline 2012 & Norte & $\mathrm{AM}$ & Boa Vista do Ramos & Urbana & Estadual & 0,3 \\
\hline 2012 & Norte & $\mathrm{AP}$ & Laranjal do Jari & Urbana & Federal & 0,4 \\
\hline 2012 & Norte & $\mathrm{AM}$ & Alvarães & Urbana & Estadual & 0,5 \\
\hline 2012 & Norte & AM & Presidente Figueiredo & Urbana & Federal & 0,5 \\
\hline 2012 & Norte & RR & Boa Vista & Urbana & Federal & 0,5 \\
\hline 2012 & Norte & TO & Miranorte & Urbana & Estadual & 0,5 \\
\hline 2012 & Norte & $\mathrm{AM}$ & Tabatinga & Urbana & Federal & 0,6 \\
\hline 2012 & Norte & $\mathrm{TO}$ & Arraias & Urbana & Estadual & 0,7 \\
\hline 2012 & Norte & $\mathrm{AM}$ & Envira & Urbana & Estadual & 0,8 \\
\hline 2012 & Norte & $\mathrm{AM}$ & Uarini & Rural & Estadual & 0,8 \\
\hline 2012 & Norte & $\mathrm{AM}$ & Uarini & Urbana & Estadual & 1,1 \\
\hline 2012 & Norte & $\mathrm{PA}$ & Marapanim & Urbana & Estadual & 1,1 \\
\hline 2012 & Norte & $\mathrm{RO}$ & \begin{tabular}{|l} 
Vilhena \\
\end{tabular} & Urbana & Federal & 1,2 \\
\hline 2012 & Norte & $\mathrm{AM}$ & Tapauã & Urbana & Estadual & 1,2 \\
\hline
\end{tabular}

Fonte: Brasil/INEP (2012). 
De uma forma geral, nos anos de 2002 e 2007 percebeu-se uma maior presença da condição de "abandono escolar" na zona urbana dos municípios da região norte. Já no ano de 2012 os municípios da zona rural constituem a maioria daqueles identificados na pesquisa. Registra-se que há a recorrência do município "Palestina do Pará" nos anos de 2002 e 2007.

Os maiores índices de abandono escolar verificados nos anos de 2002 e 2007 foram municípios como Laranjal do Jari (AP), Uiramutã (RR), Baião (PA), Assis Brasil (AC), Nova Ipixuna (PA), Palestina do Pará (PA), Altamira (PA) (no ano de 2002), Palestina do Para (PA), Acrelândia (AC), Paraná (TO), Itapiranga (AM), Pedra Branca do Amapari (AP) (no ano de 2007) e Alvarães (AM), Anori (AM), Pedra Branca do Amapari (AP), Pracuúba (AP), Xinguara (PA), Chaves (PA), Benevides (PA) (no ano de 2012).

Mais uma vez, a correspondência com os dados expostos nos apresenta a necessidade de um ensino com qualidade social aos sujeitos sob uma perspectiva integradora. A precariedade da escola, o problema no acesso e permanência e a suposta neutralidade, expõe uma faceta ideológica consentida de desmonte de sua função social.

Em contraposição, urge a necessidade de resgate da escola como integradora do conhecimento, entendendo o discente como sujeito construtor/ (re)elaborador do conhecimento, mediada essa construção pela figura do docente, resgatando-se o método ativo de formação proposto pelo pensador italiano Antônio Gramsci (GRAMSCI, 1978), de maneira que a construção do conhecimento científico, fundamental para as classes populares para a sua “elevação cultural e moral”, para ser significativo, democrático e, portanto, não excludente, necessariamente parta dos sujeitos sociais concretos, de seu mundo de necessidades, de sua cultura, folclore, diferenças, etc. (FRIGOTTO, 2008).

Por essa opção política de ensino, levam-se em conta os interesses dos alunos, seus ritmos de aprendizagem, o desenvolvimento psicológico dos mesmos, não se perdendo de vista "[...] a sistematização lógica dos conhecimentos, sua ordenação e gradação para efeitos do processo de transmissão-assimilação dos conteúdos cognitivos" (SAVIANI, 2006, p. 69)

Trata-se da assunção por parte dos docentes de um posicionamento de combate à materialização da dualidade educativa imposta aos trabalhadores, opondo-se tanto à separação entre escola técnica e escola de conhecimentos gerais, como a concepções de aprendizagem que colocam os discentes como receptáculos sobre os quais se inscrevem os saberes escolares, e que sem identificação com aquele espaço e pela imposição do trabalho precoce, abandonam possivelmente, a única oportunidade de contato com o saber sistematizado. 


\section{DISTORÇÃO IDADE-SÉRIE NO ENSINO MÉDIO 5}

A problemática da distorção idade-série se localiza de forma intensa na zona rural dos municípios desta região. Dados do ano de 2007 nos informam que o maior município da região amazônica (segunda maior região metropolitana), apresenta os maiores índices relacionados à distorção idade-série na sua zona rural (Tabela 13).

Tabela 13 - Maiores índices de distorção idade-série no ensino médio em municípios da Região Norte em 2007.

\begin{tabular}{|c|c|c|c|c|c|c|}
\hline Ano & Região & $\begin{array}{l}\text { Sigla } \\
\text { da UF }\end{array}$ & Município & $\begin{array}{c}\text { Locali- } \\
\text { zação }\end{array}$ & Rede & $\begin{array}{c}\text { Taxa de } \\
\text { distorção } \\
\text { Idade-série }\end{array}$ \\
\hline 2007 & Norte & $\mathrm{AM}$ & Manaus & Rural & Estadual & 100 \\
\hline 2007 & Norte & TO & Itacajá & Rural & Estadual & 100 \\
\hline 2007 & Norte & TO & Lagoa da Confusão & Rural & Estadual & 96,6 \\
\hline 2007 & Norte & TO & Formoso do Araguaia & Rural & Estadual & 96,2 \\
\hline 2007 & Norte & TO & Tocantínia & Rural & Estadual & 95,9 \\
\hline 2007 & Norte & $\mathrm{AM}$ & Benjamin Constant & Rural & Estadual & 95,7 \\
\hline 2007 & Norte & AM & Santo Antônio do Icá & Rural & Estadual & 94,7 \\
\hline 2007 & Norte & $\overline{\mathrm{AM}}$ & Tabatinga & Rural & Estadual & 94,7 \\
\hline 2007 & Norte & TO & Tocantinópolis & Rural & Estadual & 93,9 \\
\hline 2007 & Norte & $\mathrm{PA}$ & Capitão Poço & Rural & Estadual & 93 \\
\hline 2007 & Norte & TO & Rio Sono & Rural & Estadual & 92,9 \\
\hline 2007 & Norte & $\mathrm{AC}$ & Mâncio Lima & Rural & Estadual & 92 \\
\hline 2007 & Norte & PA & Chaves & Urbana & Estadual & 91,9 \\
\hline 2007 & Norte & $\mathrm{PA}$ & Aurora do Pará & Rural & Estadual & 91,7 \\
\hline 2007 & Norte & $\mathrm{PA}$ & Curralinho & Urbana & Estadual & 89,5 \\
\hline
\end{tabular}

Fonte: Brasil/INEP (2007).

Dos 15 municípios com os maiores índices de distorção idade-série, 13 localizam-se na zona rural. Considera-se, que este indicador deve ser entendido em sua relação com as taxas de cobertura, pois estudos do Ministério da Educação revelam que alguns esforços para ampliar a oferta de vagas no ensino médio, tendo a oferta da EJA como uma de suas principais ações, podendo causar, num primeiro momento, a elevação da distorção-idade série, decorrente, portanto, da ampliação de vagas e não necessariamente da ineficiência das políticas públicas.

O INEP não disponibiliza dados de distorção idade-série do ano de 2002. 
A Tabela 14 revela mudanças neeses índices quanto à concentração desta problemática. Os dados informam que, dentre os 15 (quinze) maiores índices de distorção idade-série em 2012, 11 (onze) estão localizados no estado do Amazonas. Observe-se a tabela abaixo:

Tabela 14 - Maiores índices de distorção idade-série no ensino médio em municípios da Região Norte no ano de 2012.

\begin{tabular}{|c|c|c|c|c|c|c|}
\hline Ano & Região & $\begin{array}{c}\text { Sigla } \\
\text { da UF }\end{array}$ & Município & $\begin{array}{c}\text { Locali- } \\
\text { zação }\end{array}$ & Rede & $\begin{array}{c}\text { Taxa de } \\
\text { distorção } \\
\text { Idade-série }\end{array}$ \\
\hline 2012 & Norte & $\mathrm{AM}$ & Lábrea & Rural & Estadual & 100 \\
\hline 2012 & Norte & $\mathrm{AM}$ & Amatura & Rural & Estadual & 98,6 \\
\hline 2012 & Norte & $\mathrm{AP}$ & Oiapoque & Rural & Estadual & 96,1 \\
\hline 2012 & Norte & $\mathrm{AM}$ & São Paulo de Olivença & Rural & Estadual & 93,7 \\
\hline 2012 & Norte & $\mathrm{AM}$ & Novo Airão & Rural & Estadual & 93,3 \\
\hline 2012 & Norte & $\mathrm{AM}$ & Ipixuna & Rural & Estadual & 93,1 \\
\hline 2012 & Norte & $\mathrm{AM}$ & Alvarães & Rural & Estadual & 92,9 \\
\hline 2012 & Norte & AM & Jutaí & Rural & Estadual & 92,7 \\
\hline 2012 & Norte & $\mathrm{AM}$ & Codajás & Rural & Estadual & 91,3 \\
\hline 2012 & Norte & $\mathrm{AM}$ & Uarini & Rural & Estadual & 91,1 \\
\hline 2012 & Norte & $\mathrm{AM}$ & Japurá & Rural & Estadual & 89,9 \\
\hline 2012 & Norte & PA & Bom Jesus do Tocantins & Rural & Estadual & 89,2 \\
\hline 2012 & Norte & $\mathrm{PA}$ & Conceição do Araguaia & Rural & Estadual & 89,2 \\
\hline 2012 & Norte & TO & Goiatins & Rural & Estadual & 87,7 \\
\hline 2012 & Norte & $\mathrm{AM}$ & Fonte Boa & Rural & Estadual & 87,6 \\
\hline
\end{tabular}

Fonte: Brasil/INEP (2012).

Quanto à localização da problemática de distorção idade-série no ano de 2012, verificamos que não houve mudança em relação à anterior, no que se refere ao protagonismo negativo da zona rural dos municípios, que continua concentrando os piores índices dessa distorção.

Percebemos ainda os altos índices de distorção idade-série como um problema localizado em municípios da região amazônica de menor crescimento econômico. Apresentamos exemplos que referendam a análise dos dados referentes a 2012, destacando-se o estado do Amazonas, com maior incidência nos municípios Lábrea e Amatura, que apresentam índices de distorção idadesérie de 100\% e 98,6\%, respectivamente. No cômputo geral, o Amazonas obteve os maiores índices nesse ano, visto que dos 15 municípios citados, onze são amazonenses (Tabela 14). 
Inegavelmente, o estado do Amazonas concentrou os piores índices de distorção idade-série em 2012. Este problema se agrava quando se constata que os municípios citados localizam-se na zona rural, predominantemente na rede estadual de ensino.

Apresentamos, a seguir, os menores índices de distorção idade-série registrados no ano de 2007, ressaltando que nesse momento os menores índices dessa distorção no ensino estão concentrados na zona urbana, conforme se observa na Tabela 15.

Tabela 15 - Menores índices de distorção idade-série no ensino médio em municípios da Região Norte em 2007.

\begin{tabular}{|l|l|c|l|c|c|c}
\hline Ano & Região & $\begin{array}{c}\text { Sigla } \\
\text { da UF }\end{array}$ & \multicolumn{1}{|c|}{ Município } & $\begin{array}{c}\text { Locali- } \\
\text { zação }\end{array}$ & Rede & $\begin{array}{c}\text { Taxa de distorção } \\
\text { Idade-série }\end{array}$ \\
\hline 2007 & Norte & RR & Boa Vista & Urbana & Federal & 7,9 \\
\hline 2007 & Norte & AC & Rio Branco & Urbana & Federal & 10,2 \\
\hline 2007 & Norte & RO & Colorado do Oeste & Urbana & Estadual & 17,4 \\
\hline 2007 & Norte & RO & Colorado do Oeste & Rural & Federal & 17,6 \\
\hline 2007 & Norte & TO & Palmas & Urbana & Federal & 19,3 \\
\hline 2007 & Norte & RR & Mucajaí & Urbana & Estadual & 19,4 \\
\hline 2007 & Norte & RO & Machadinho D'oeste & Urbana & Estadual & 20,5 \\
\hline 2007 & Norte & RR & Caroebe & Urbana & Estadual & 22,3 \\
\hline 2007 & Norte & RR & Bonfim & Urbana & Estadual & 22,4 \\
\hline 2007 & Norte & AM & Manaus & Urbana & Federal & 22,9 \\
\hline 2007 & Norte & RR & São João da Baliza & Urbana & Estadual & 27,7 \\
\hline 2007 & Norte & PA & Belém & Urbana & Federal & 27,8 \\
\hline 2007 & Norte & RR & Pacaraima & Urbana & Estadual & 28,3 \\
\hline 2007 & Norte & RO & Vilhena & Urbana & Estadual & 28,9 \\
\hline 2007 & Norte & RR & Alto Alegre & Urbana & Estadual & 28,9 \\
\hline
\end{tabular}

Fonte: Brasil/INEP (2007).

Com base nos dados apresentados, pode-se depreender que os menores e, portanto, mais qualificados índices que se distanciam do problema da distorção idade-série concentram-se na rede escolar federal, com destaque para zona urbana, uma vez que dos cinco menores índices de distorção, quatro pertencem a esta rede de ensino em apenas um município localizado na zona rural.

Outro dado da Tabela 15 chama a atenção quando se afirma que as duas regiões metropolitanas da Amazônia, ambas na rede federal, estão entre os menores índices de distorção idade-série. Este dado sugere que o ensino 
médio de maior qualidade é ofertado nos centros urbanos e, principalmente na rede federal de ensino. Destacamos também que os estados que concentram os menores índices são Rondônia (RO) e Roraima (RR), onde, dos 15 municípios com maiores índices de distorção idade-série, 11 pertencem a esses estados.

O ensino de qualidade referenciada a que nos referimos diz respeito à assunção de uma postura pedagógica do educador em desenvolver um processo formativo em que o trabalhador tenha o direito a uma formação ominilateral (GRAMSCI, 1978), opondo-se a formações aligeiradas. Esse compromisso parte do princípio de que as camadas populares necessitam se apropriar "[...] das ferramentas culturais necessárias à luta social que travam para se libertar das condições de exploração em que vivem” (SAVIANI, 2006, p. 71).

No ano de 2012, os menores índices concentraram-se novamente na zona urbana e na rede federal, com destaque aos estados de Tocantins e Rondônia, em detrimento da zona rural, que apresenta apenas um entre os 15 municípios. Referimo-nos à zona rural do município de Epitaciolândia (AC) entre os menores índices de distorção idade-série (Tabela 16).

Tabela 16 - Menores índices de distorção idade-série no ensino médio em municípios da Região Norte em 2012.

\begin{tabular}{|c|c|c|c|c|c|c|}
\hline Ano & Região & $\begin{array}{l}\text { Sigla } \\
\text { da UF }\end{array}$ & Município & \begin{tabular}{|c|} 
Locali- \\
zação
\end{tabular} & Rede & $\begin{array}{c}\text { Taxa de distorção } \\
\text { Idade-série }\end{array}$ \\
\hline 2012 & Norte & TO & Paraíso do Tocantins & Urbana & Federal & 7,7 \\
\hline 2012 & Norte & TO & Porto Nacional & Urbana & Federal & 7,7 \\
\hline 2012 & Norte & $\mathrm{TO}$ & Palmas & Urbana & Federal & 8,7 \\
\hline 2012 & Norte & $\mathrm{RR}$ & Boa Vista & Urbana & Federal & 9,2 \\
\hline 2012 & Norte & TO & Araguaína & Urbana & Federal & 10,5 \\
\hline 2012 & Norte & AC & Epitaciolândia & Rural & Estadual & 11,1 \\
\hline 2012 & Norte & $\mathrm{RR}$ & São Luís & Urbana & Estadual & 11,8 \\
\hline 2012 & Norte & TO & Tupirama & Urbana & Estadual & 12,7 \\
\hline 2012 & Norte & $\mathrm{RO}$ & Cacoal & Urbana & Federal & 12,8 \\
\hline 2012 & Norte & RO & Ji-Paraná & Urbana & Federal & 12,9 \\
\hline 2012 & Norte & $\mathrm{RO}$ & Vilhena & Urbana & Federal & 13,6 \\
\hline 2012 & Norte & $\mathrm{AC}$ & Xapuri & Urbana & Federal & 14,3 \\
\hline 2012 & Norte & $\mathrm{RO}$ & Cabixi & Urbana & Estadual & 14,8 \\
\hline 2012 & Norte & AP & Macapá & Urbana & Federal & 14,8 \\
\hline 2012 & Norte & TO & Presidente Kennedy & Urbana & Estadual & 16,1 \\
\hline
\end{tabular}

Fonte: Brasil/INEP (2012). 
De forma geral, nos anos de 2007 e 2012, destacam-se os elevados índices de distorção no ensino nos municípios do arquipélago do Marajó, no Pará, sobretudo em Chaves e Curralinho, agravado pelos índices negativos de desenvolvimento humano. O estado do Amazonas também se destacou em 2012, por englobar a maioria dos municípios com índices negativos.

Dessa forma, a zona rural e alguns municípios da região amazônica com pouca expressão econômica obtiveram os maiores índices de distorção idadesérie, enquanto as capitais e os centros regionais em geral apresentaram índices positivos em cada período verificado.

Esta observação é confirmada pelos os dados sobre distorção idade-série em que as capitais como Belém (PA), Manaus (AM), Palmas (TO) e Boa Vista (RR), bem como municípios importantes na região como Vilhena (RO) e Tucuruí (PA) estão entre aqueles que apresentaram os menores índices de distorção nos períodos verificados.

Não obstante de se reconhecer a problemática do ensino em escolas no interior dos municípios da Amazônia, é necessário compreender, como alternativa, a perspectiva de ensino médio integrado, pressupondo uma gestão democrática e o fomento de um processo participativo no ambiente escolar, exigindo tanto de educadores quanto de educandos a constituição de uma identidade com o espaço e com a sua própria realidade, para além do ensinante e do aprendiz, buscando assim minimizar os efeitos do abandono ou evasão escolar e, por conseguinte, da distorção idade-série dos alunos.

\section{CONSIDERAÇÕES FINAIS}

A aprovação, o abandono e os processos que se refletem no atraso escolar configuram-se como mecanismos inerentes ao funcionamento da escola nas sociedades capitalistas, contribuindo, portanto, para a sua reprodução. A dualidade educacional e os obstáculos de acesso e permanência produzidos por essa escola repercutem intensamente sobre a população mais pobre.

Em síntese, essa problemática materializa-se no ensino médio brasileiro, marcantemente em municípios da região amazônica, de modo que o estado do Tocantins concentra os melhores índices de aprovação e abandono, em contraposição ao estado do Pará, que concentra os municípios com os mais altos índices de reprovação.

Sobre o abandono escolar, os municípios paraenses concentram os mais altos índices, particularmente no sul e sudoeste do estado, onde há grandes fluxos migratórios decorrentes do crescimento desordenado e da dependência econômica da região aos grandes projetos. 
Quanto à distorção idade-série, os estados do Amazonas e Pará concentram as maiores distorções, sendo relevante, neste último estado, a participação dos municípios da região do Marajó (microrregião paraense que apresenta os piores índices de desenvolvimento humano de todo o estado). Ressalte-se que este indicador deve ser analisado em relação às taxas de cobertura, podendo ser decorrente do aumento da oferta de vagas para adultos.

Os quatro indicadores analisados (aprovação, reprovação, abandono e distorção idade-série) convergem no ponto relativo à localização dos piores índices nas escolas da zona rural. Mesmo reconhecendo que os problemas no fluxo no ensino médio se localizam majoritariamente na zona urbana e sob a cobertura das redes estaduais de ensino, deve-se considerar também que proporcionalmente, em números absolutos há uma menor concentração de alunos na zona rural, em comparação à zona urbana, o que pode contribuir para mascarar a maior incidência negativa da zona rural.

Nestas condições destacamos que a juventude amazônida se insere, evade ou é reprovada várias vezes na escola, como reflexo da necessidade imperiosa de subsistência a partir do trabalho precoce. O conjunto de dados e análises nos oferecem bases relevantes para definirmos o ensino médio brasileiro como projeto inacabado e com problemas estruturais que passam pelos investimentos para a sua manutenção.

Portanto, o projeto de ensino médio como formação e realização dos sujeitos é refutado. Os dados nos revelam problemas estruturais que sequer garantem a matrícula neste nível de ensino de um número considerável de jovens, adultos e/ou trabalhadores. Este déficit é igualmente comprometido se observarmos que se trata de um prolongamento de um profundo problema nacional, com incidência principalmente sobre a população mais pobre.

De uma forma geral, a mudança nesse quadro negativo passa pela necessidade de maior investimento público às escolas da Região Norte, a partir da formulação de políticas públicas educacionais que assumam como prioridade o estabelecimento de processos de formação e qualificação de professores, além de uma maior infraestrutura das escolas, de modo a elevar a identificação dos jovens e adultos com esta etapa de ensino, e evitar problemas no seu fluxo, como o abandono ou a reprovação desses alunos.

A escola, por sua vez, precisa estar sintonizada com a formação de sujeitos comprometidos com os rumos pedagógicos e políticos da escola, com a definição de objetivos de ensino e fortalecimento das entidades colegiadas. E esta perspectiva de educação integradora requer um sujeito para além do domínio dos conhecimentos científicos reorganizados e reinterpretados no ambiente escolar, pressupondo um educador que domine também os conhecimentos relativos ao exercício dos 
direitos e deveres na sociedade, tal como orienta Gramsci (1978) com relação aos conhecimentos da societas rerum e aos da societas hominum, respectivamente.

Entendemos, neste caso, que essas políticas precisam ser criadas ou fortalecidas nas zonas rurais e nos municípios longínquos e distantes dos centros econômicos da região amazônica, particularmente nos municípios caracterizados pela pobreza de uma juventude com pouca ou nenhuma presença política do Estado e, portanto, com um futuro gravemente ameaçado.

Isto posto, tecidas tais considerações sobre o ensino médio brasileiro, com destaque para a luta dos trabalhadores por uma perspectiva educacional que supere a dualidade formativa, mas impregnada de valores e atitudes pedagógicas integradoras que possibilitem a formação ampla e continuada dos sujeitos, expusemos as análises que permitem um diagnóstico do ensino médio na Amazônia, apontando estratégias voltadas para a superação dos problemas que impedem uma educação integral.

Ademais, se os dados atestam que o ensino médio em espaços rurais apresenta índices altos de abandono, reprovação e distorção idade-série, há de se considerar a necessidade de se continuar pautando o ensino médio integrado como a perspectiva necessária para que haja articulação de saberes nessa região, da memória dos aprendizes, como forma de propiciar uma formação que oportunize a permanência na escola e o sucesso na aprendizagem, além de se consubstanciarem políticas públicas que favoreçam, em sentido mais amplo, maior distribuição de renda, em um estágio primário, que permita à juventude viver o tempo do estudo, da formação escolar, sem a necessidade de interromper a vivência das etapas de escolarização sob a negatividade do trabalho precoce.

\section{REFERÊNCIAS}

ARAUJO, R. M. de L. Desenvolvimento de competências profissionais: as incoerências de um discurso. 2001. Tese (Doutorado) - Universidade Federal de Minas Gerais, Belo Horizonte, 2001.

.; RODRIGUES, D. do S. Filosofia da Práxis e Ensino Integrado: para além da questão curricular. Revista do NETE, Belo Horizonte, 2010.

BRASIL. Ministério da Educação. Lei de Diretrizes e Bases da Educação Nacional. Brasília, DF: Senado Federal, 1996.

Proposta Pedagógica: Ensino Médio Integrado à Educação Profissional In: FRIGOTTO, G.o; CIAVATTA, M.; RAMOS, M. Concepção e experiências de ensino integrado: a gênese do Decreto n. 5.154/2004: um debate no contexto controverso da democracia restrita. Brasília, DF: Ministério da Educação, 2006. (Boletim 7). 
Parâmetros Curriculares Nacionais (Ensino Médio). Brasília, DF: Ministério da Educação/Secretaria de Educação Média e Tecnológica, 2000. Disponível em: <http://portal.mec.gov.br/seb/arquivos/pdf/cienciah.pdf $\geq$. Acesso em: 17 jul. 2013.

Censo da Educação Básica: 2012 - Resumo Técnico. Brasília, DF: INEP, 2013

Taxas de distorção idade-série escolar na Educação Básica. Brasília, DF: INEP, 2014. Disponível em: <http://dados.gov.br/dataset/taxas-de-distorcao-idade-serieescolar-naeducacao-basica $\geq$. Acesso em: 20 jan. 2014.

CAMPELLO, A. M. Dualidade Educacional (Verbete). In: RAMOS, M. Dicionário da Educação Profissional em Saúde. Rio de Janeiro: Fiocruz/EPSJV, 2009.

CURY, C. R. J. A educação básica no Brasil. Educação e Sociedade, Campinas, v. 23, n. 80, 2002.

FRANCO, M. C. A formação integrada: a escola e o trabalho como lugares de memória e de identidade. In: FRIGOTTTO, G.; CIAVATTA, M.; RAMOS, M. (Orgs.). Ensino Médio Integrado: concepções e contradições. São Paulo: Cortez, 2005.

; RAMOS, M. Ensino Médio e Educação Profissional no Brasil: dualidade e fragmentação. Revista Retratos da Escola, Brasília, v. 5, n. 8, p. 27-41, jan./jun. 2011. Disponível em: <http//www.esforce.org.br>. Acesso em 27 fev. 2013.

; FRIGOTTO, G.; RAMOS, M. N. A gênese do Decreto nº. 5.154/2004: um debate no contexto controverso da democracia restrita. Trabalho necessário. Revista Eletrônica do NEDDATE. Disponível em: < http://www.uff.br/trabalhonecessario/ MMGTN3.htm>. Acesso em: 9 ago. 2005.

FRIGOTTO, G.; CIAVATTA, M.; RAMOS, M. (Orgs.). Ensino Médio Integrado: concepções e contradições. São Paulo: Cortez, 2005.

FRIGOTTO, G. Juventude, trabalho e educação no Brasil: perplexidades, desafios e perspectivas. In: NOVAES, R.; VANNUCHI, P. et al. Juventude e sociedade: trabalho, educação, cultura e participação. São Paulo: Fundação Perseu Abramo, 2004.

FRIGOTTO, G. Os projetos societários do Brasil em disputa e as relações de inclusão e exclusão da escola pública. In: FÓRUM DE ENSINO MÉDIO: INTERROGAÇÕES, DESAFIOS E PERSPECTIVAS. 2008. Belém. Anais... Belém: SEDUC, 2008.

FORRESTER, V. O horror econômico. São Paulo: Ed. UNESP, 1997.

GRAMSCI, A. Os intelectuais e a organização da cultura. São Paulo: Civilização Brasileira, 1978.

GARCIA, S. R. de O. Ensino Médio e educação profissional: breve histórico a partir da LDBEN no 9394/96. In: AZEVEDO, J. C. de; REIS, J. T. (Orgs). Reestruturação do ensino médio: pressupostos teóricos e desafios da prática. São Paulo: Fundação Santillana, 2013. 
GRABOWSKI, G. Ensino Médio Integrado à Educação Profissional. In: TVescola: Programa Salto para o Futuro. EJA: formação técnica integrada ao ensino médio. Boletim 7, Rio de Janeiro, maio-jun. 2006. Disponível em: < http://www.tvbrasil.org.br/fotos/ salto/series/161432Ensinomedio.pdf>. Acesso em: 20 ago. 2013.

MARX. K. Manuscritos econômicos filosóficos e outros textos escolhidos. São Paulo: Abril, 1978. (Coleção os Pensadores).

OCDE-Organização para a Cooperação e Desenvolvimento Econômico. Relatório da OCDE para o Brasil. São Paulo: OCDE Brasil, 2013. Disponível em: <http://www.oecd.org/brazil/\&prev=/ search $\% 3 F q \% 3 D o c d e \% 2 B b r a s i 1 \% 26 b i w \% 3 D 1024 \% 26$ bih\%3D499>. Acesso em: 17 jul. 2013.

PARÁ. Secretaria de Estado de Educação. O ensino médio integrado no Pará como política pública. Belém: SEDUC/SAEN/DEMP, 2008.

OLIVEIRA, R. de; GOMES, A. M. A expansão do ensino médio. Escola e Democracia. Revista Retratos da Escola, Brasília, v. 5, n. 8, p. 69-81, jan./jun. 2011. Disponível em: $<$ http//www.esforce.org.br>. Acesso em: 17 jul. 2013.

KUENZER, A. Z. (Org.). O ensino médio para os que vivem do trabalho: construindo uma nova concepção. In: Ensino Médio: construindo uma proposta para os que vivem do trabalho. 5. ed. São Paulo: Cortez, 2007.

A pedagogia da fábrica: as relações de produção e a educação do trabalhador. São Paulo: Cortez, 2000.

SLEB, V. A implantação do programa ensino médio inovador e sua relação com os dados de fluxo escolar. Projeto de Qualificação. Curitiba: UFPR, 2013.

SAVIANI, D. (1997). A nova Lei da Educação. LDB, limite, trajetória e perspectivas. 8. ed. São Paulo: Autores Associados, 2006.

. O choque teórico da politecnia. Trabalho, Educação e Saúde, Rio de Janeiro, n. 1, p. 131-152, 2003. 